\title{
Antinephritic Effect of OKY-046, a Thromboxane A Synthetase Inhibitor (1) Effects on Crescentic-Type Anti-GBM Nephritis in Rats
}

\author{
Tadashi NAGAMATSU, Yoshihito TSUKUSHI, Mikio ITO, \\ Nobuyuki KONDO and Yoshio SUZUK! \\ Department of Pharmacology. Faculty of Pharmacy, Meijo University. \\ Tenpaku-cho. Tenpaku-ku. Nagoya 468, Japan
}

Accepted January 5, 1989

\begin{abstract}
To induce crescentic-type anti-glomerular basement membrane (antiGBM) nephritis, male Sprague-Dawley rats were immunized with rabbit $\boldsymbol{r}$-globulin in Freund's complete adjuvant following i.v. injection of anti-GBM serum. At the same time, original type anti-GBM nephritis was induced in other rats by anti-GBM serum only. The animals with crescentic-type anti-GBM nephritis showed significantly higher platelet aggregability than that in rats with original-type anti-GBM nephritis at days 5,10 and 40 after anti-GBM serum administration, respectively. To estimate the antinephritic effect of OKY-046, a thromboxane A synthetase inhibitor, it was given orally to rats at doses of $0.5,2.5$ or $20 \mathrm{mg} / \mathrm{kg}$ for 39 days after anti-GBM serum. OKY-046 (20 mg/ $\mathrm{kg})$ significantly inhibited the increase in both urinary protein and plasma cholesterol levels (40\% and $35 \%$ vs. control, respectively). Moreover, when examined by light microscopy, this drug remarkably prevented histological involvement of the glomeruli. OKY -046 at $20 \mathrm{mg} / \mathrm{kg}$ had suppressed the hyperaggregability of platelets by $77 \%$ by day 40 as compared with the control, but doses of 0.5 and $2.5 \mathrm{mg} / \mathrm{kg}$ did not. It is concluded from these data that OKY-046 has beneficial effects on crescentic-type anti-GBM nephritis and may act through inhibition of not only platelet $T \times A_{2}$ but also glomerular $T \times A_{2}$ in its action to prevent histological alterations.
\end{abstract}

We have investigated antinephritic drugs by using experimental glomerulonephritis, especially anti-glomerular basement membrane (GBM) nephritis in rats. The pathogenesis of this model of nephritis has been widely studied for over two decades, and it has been suggested that a coagulant system could be implicated in the process of nephritis development (1-6). The antinephritic effects of anti-coagulant drugs, warfarin (7) and heparin $(3,8,9)$, on anti-GBM nephritis were evaluated. Recently, much attention has been focused on anti-platelet drugs as antinephritic drugs since it has been demonstrated that dipyridamole is experimentally and clinically effective against glomerulonephrits (10-12). Furthermore, in response to many vasoconstrictors such as angiotensin II, vasopreesin, histamine and epinephrine (13.
14). cultures glomeruli and cultured mesangial cells can produce prostaglandins and thromboxane $\mathrm{A}_{2}\left(\mathrm{TxA}_{2}\right)$ that are secreted into the medium. Additionally, there is much evidence indicating that glomeruli obtained from rats suffering from various types of glomerulonephritis ehnance the production of prostaglandins and $T \times A_{2}$ (15). $T x A_{2}$ is a potent inducer of platelet aggregation and a vasoconstrictor $(16,17)$. Thus, it is very likely that $\mathrm{TxA}_{2}$ derived from platelets or the mesangium can be attributed to the development of glomerulonephritis. Therefore, many investigators have studied the antinephritic effects of thromboxane $A$ synthetase inhibitors $(18-20)$. We also have reported that Y-19018, a thromboxane A synthetase inhibitor, inhibits the development of crescentic type anti-GBM nephritis in rats (21). How- 
ever, the antinephritic effect of thromboxane A synthetase inhibitors has been controversia!.

In this study we 1) studied the time course of platelet aggregability in original and crescentic-type anti-GBM glomerulonephritis and 2) examined the antinephritic effect of another thromboxane A synthetase inhibitor. OKY-046, using crescentic-type anti-GBM nephritis.

\section{Materials and Methods}

1. Animals: Male Sprague-Dawley rats (Sizuoka Jikken Doubutsu Kyodo Kumiai) weighing 160-170 g were used in all experiments.

2. Experimental nephritis: Rats were intravenously injected with 0.56 or $1 \mathrm{ml} / \mathrm{rat}$ of anti-GBM serum, which was produced in rabbits as reported (5). Original-type antiGBM nephritis was induced by the injection of anti-GBM serum alone. On the other hand. crescentic-type anti-GBM nephritis was induced by the injection of anti-GBM serum followed by subcutaneous immunization with $6.5 \mathrm{mg}$ of rabbit $\gamma$-globulin in $0.25 \mathrm{ml}$ of Freund's complete adjuvant, injected into the hind foot pads the next day.

3. Determination of platelet aggregability in whole blood (22): To determine the changes in platelet aggregability in nephritic rats after the injection of anti-GBM serum, $2.25 \mathrm{ml}$ of blood was gently drawn, prevenously, from the renal vein into a disposable syringe containing $0.25 \mathrm{ml}$ of $3.18 \%$ sodium citrate and then left for one hour at room temperature. We collected the blood from the renal vein since we thought that the renal blood can give us information about the glomeruli under nephritis. We determined platelet aggregability in both original and crescentic-types of anti-GBM nephritis on days $1,3,5,10,20$. 30 and 40 .

Platelet aggregability was measured by whole blood aggregometer, model C-560 (Crono-log Co.). Five hundred microliters of blood were added to $495 \mu$ of $0.9 \%$ saline in a small aggregometer cuvette. This cuvette was maintained at $37^{\circ} \mathrm{C}$ by a heated block and the contents were stirred with a flea magnet. An electrode was inserted into the sample. Five micrograms of collagen (Collagen re- agent Horm, Hormon-Chehen) was then added to a sample in the cuvette. Results are represented as the impedance (ohm) between the two electrodes at $5 \mathrm{~min}$ after the addition of aggregating agents.

4. Drug administration: $O K Y-O 46,(E)-3-$ [4 - (1 - imidazolylmethyl)phenyl] - 2 - methylpropenoic acid hydrochloride monohydrate (Kissei Yakuhin. Ono Yakuhin), was used (Fig. 1). OKY-046 was dissolved in distilled water. Animals received this orally in a volume of $1 \mathrm{ml} / 100 \mathrm{~g}$ of body weight. OKY-046 was administered daily at a dose of $0.5,2.5$ or 20 $\mathrm{mg} / \mathrm{kg}$ (p.o.) for 39 days after the injection of rabbit $\gamma$-globulin. Ujiie et al. (23) demonstrated that serum $\mathrm{TxB}_{2}$ level fell to nearly 0 in the whole blood of rabbits fed on high lipid diets by the oral administration of $O K Y$ 046 at 10 or $100 \mathrm{mg} / \mathrm{kg}$, twice a day.

In addition to the drug-treated group. nontreated nephritic (control) and normal groups were used in both experiments.

5. General condition, body weight and urine volume: General condition was observed, and body weight and urine volume were determined during the experiment.

6. Urine, blood and kidney: Twenty-four hour urine samples were obtained on days 0. 5, 9, 29 and 39 after the injection of antiGBM serum. Blood samples were obtained from the tail vein on days $7,15,25$ and 36 after the injection of anti-GBM serum. In addition, on day 40 , each animal was anesthetized with sodium pentobarbital ( 30 $\mathrm{mg} / \mathrm{kg}$ ) after the last collection of a urine sample, and a blood sample was collected from the renal vein to determine platelet aggregability. The kidneys were then immediately isolated and used in histopathological preparations.

7. Determination of biochemical parameters in urine and plasma: The protein content in urine was determined by the

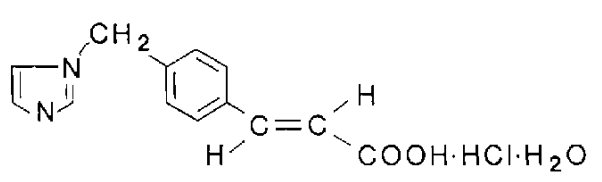

Fig. 1. Chemical structure of OKY-046, (E)-3-[4(1 - imidazolylmethyl)phenyl] - 2 - methyl - propenoic acid. 
method of Kingsbury et al. (24) and expressed as mg per day. Cholesterol content in plasma was determined with a commercial assay kit (Determina TC-5, Kyouwa Medix Co., Ltd.) (25). Urea nitrogen content in plasma was determined by the ureaseindophenol spectrophotometry assay (26). Both cholesterol and urea nitrogen contents were reported as $\mathrm{mg}$ per $1 \mathrm{dl}$ of plasma.

8. Light microscopic studies: The kidney was dehydrated stepwise and fixed by immersing the tissue into progressively higher concentrations of alcohol. Thereafter, the tissue was embedded in paraffin and cut into $3-\mu \mathrm{m}$ thick sections. The sections were stained with hematoxylin and eosin, periodic acid-Schiff, and Masson's trichrome. Fifty glomeruli per section were observed under a light microscope for evaluating crescent formation, adhesion to Bowman's capsule of the capillary wall and fibrinaid necrosis. Each histopathological parameter was calculated as an index for crescent formation, for adhesion to Bowman's capsule of the capillary wall and for fibrinoid necrosis as reported previously (27). Each histological parameter was graded normal ( 0 point), mild (1 point), moderate ( 2 point) and severe ( 3 point) according to the extent of alteration. The number of glomeruli corresponding to each score was represented as $n_{0}, n_{1}, n_{2}$ and $n_{3}$. Indexes for crescent formation $(\mathrm{Cl})$, adhesion to Bowman's capsule of the capillary wall (Al) or for fibrinoid degeneration (FI) were calculated as follows: $\mathrm{Cl}, \mathrm{Al}$ or $\mathrm{FI}=\left(1 \times \mathrm{n}_{1}\right)+\left(2 \times \mathrm{n}_{2}\right)+\left(3 \times \mathrm{n}_{3}\right)$.

9. Statistical analysis: All data were presented as the mean \pm S.D., and the significance of difference was determined by analysis of variance, Student's $t$-test or MannWhitney's $U$-test. Inhibitory percentage was calculated as follows:

inhibitory percentage (\%)

$$
=\frac{\text { Control-Test drug }}{\text { Control-Normal }} \times 100
$$

\section{Results}

1. Changes in platelet aggregability after injection of anti-GBM serum (Fig. 2)

Platelet aggregability had significantly increased since day 5 in nephritic rats com-

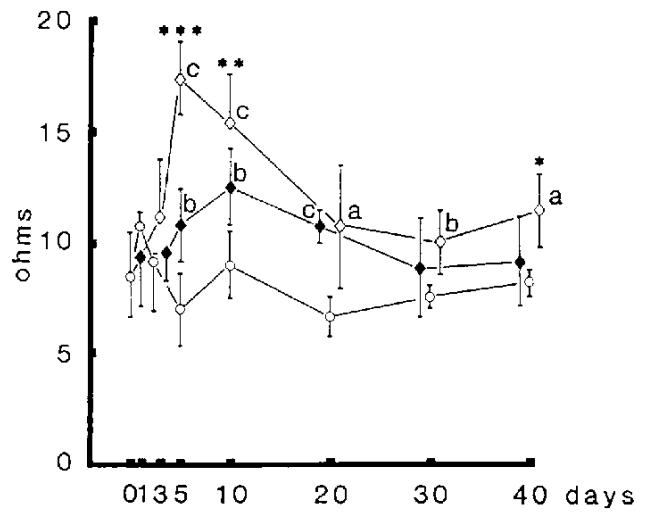

Fig. 2. Changes in collagen-induced platelet aggregation after injection of anti-GBM serum. The values are expressed as the mean \pm S.D. obtained from 8 rats. Normal $(O)$ : untreated rats, Origina!type anti-GBM nephritis ( ) : Rats were i.v. injected with anti-GBM serum, Crescentic-type anti-GBM nephritis $(O)$ : Rats received i.d. injection of rabbit $\gamma$-globulin in FCA the next day after i.v. injection of anti-GBM serum. $\mathbf{a}, \mathbf{b}$ and $\mathbf{c}$ indicate significant differences from the normal values at $P<0.05,0.01$ and 0.001 , respectively. * ** and ** indicate significant differences from original-type at $P<0.05$. 0.01 and 0.001 . respectively.

pared to that in normal rats. Although on days 30 and 40 , platelets from rats with originaltype anti-GBM nephritis showed only slightly higher aggregability than that in normal rats, the platelet aggregability in rats with crescentic-type anti-GBM nephritis was significantly higher than that in normal rats. In the rats with crescentic-type anti-GBM nephritis throughout the experimental period, and especially on days 5, 20 and 40, this difference was notable.

\section{General condition}

No rats given OKY-046 died during the experiments. A similar amount of rat chow was consumed by both the control and OKY 046 groups. In addition, none of the rats given OKY-046 exhibited any abnormal behavior or diarrhea.

\section{Body weight and urine volume (Table 1)}

The control and OKY-046 groups showed lower body weights than that of the normal group on days 20 and 40 . Both control and OKY-046-treated rats showed a similar course of weight gain. The rats injected with anti-GBM serum excreted less urine than 
Table 1. Changes in body weight and urine volume during administration of OKY-046 in crescentic-type anti-GBM nephritis in rats

\begin{tabular}{lccccc}
\hline Groups & $\mathrm{N}$ & & 1 & 20 & 40 Days \\
\hline Normal & 16 & B.W. & $160.0 \pm 8.0$ & $243.1 \pm 16.5$ & $309.5 \pm 21.2$ \\
& & U.V. & $13.6 \pm 2.2$ & $15.7 \pm 1.5$ & $15.1 \pm 2.0$ \\
Control & 19 & B.W. & $163.9 \pm 6.0$ & $216.2 \pm 16.4^{*}$ & $272.0 \pm 21.7^{*}$ \\
& & U.V. & $10.2 \pm 1.6^{*}$ & $10.2 \pm 2.5^{*}$ & $15.8 \pm 3.0$ \\
OKY-046 & 10 & B.W. & $161.5 \pm 4.7$ & $230.0 \pm 16.1^{*}$ & $275.8 \pm 18.3$ \\
$0.5 \mathrm{mg} / \mathrm{kg}$ & & U.V. & $9.5 \pm 2.0$ & $15.0 \pm 2.2^{*}$ & $14.6 \pm 1.4$ \\
OKY-046 & 10 & B.W. & $163.6 \pm 6.6$ & $226.3 \pm 16.5$ & $277.0 \pm 19.8$ \\
$2.5 \mathrm{mg} / \mathrm{kg}$ & & U.V. & $10.0 \pm 1.4$ & $15.0 \pm 1.3^{*}$ & $15.9 \pm 2.3$ \\
OKY-046 & 10 & B.W. & $165.8 \pm 4.6$ & $208.4 \pm 6.3$ & $276.2 \pm 13.7$ \\
$20 \mathrm{mg} / \mathrm{kg}$ & & U.V. & $11.2 \pm 1.1$ & $14.9 \pm 1.0^{*}$ & $16.1 \pm 1.6$ \\
\hline
\end{tabular}

Numbers indicate the mean \pm S.D. "shows a significant difference from the normal rats at $P<0.05$. *shows a significant difference from the control at $P<0.05$. B.W.: body weight $(\mathrm{g})$. U.V.: urine volume (ml).

normal rats on days 1 and 20. However. on day 20 OKY-046 administer rats showed an increase in urine volume, which was previously at a nearly norma! level, in comparison with the control rats. The difference in urine volume among them was negligible at the end of the experiment.

4. Effect of OKY-046 on biochemical parameters in urine and plasma

Urinary protein (Fig. 3): Normal rats excreted about $10 \mathrm{mg} /$ day of protein into urine throughout the experimental period. Control rats revealed proteinuria that contained from 100 to $150 \mathrm{mg} /$ day of protein on day 1 after the injection of anti-GBM serum. Thereafter. proteinuria remained at a level of about 150 $\mathrm{mg} /$ day of protein. On the other hand. $20 \mathrm{mg} /$ $\mathrm{kg}$ of OKY-046 resulted in a urinary protein level of about $40 \%$ less than that in the control rats on days 20 and 30 which was a significant difference. The rats administered 0.5 or $2.5 \mathrm{mg} / \mathrm{kg}$ of OKY-046, however, displayed proteinuria at a level similar to that of the control rats.

Plasma cholesterol (Table 2): The content of cholesterol in the control rats increased to a level of about $150 \mathrm{mg} / \mathrm{dl}$ day 8 after the injection of anti-GBM serum. OKY-046 (20 $\mathrm{mg} / \mathrm{kg}$ ) significantly decreased plasma cholesterol by about $75 \%$ of that of the control group by day 22. However, 0.5 and $2.5 \mathrm{mg} /$ $\mathrm{kg}$ of OKY-046 no effect on the serum cholesterol level.

Plasma urea nitrogen (Table 3): The control rats had a slightly higher level of

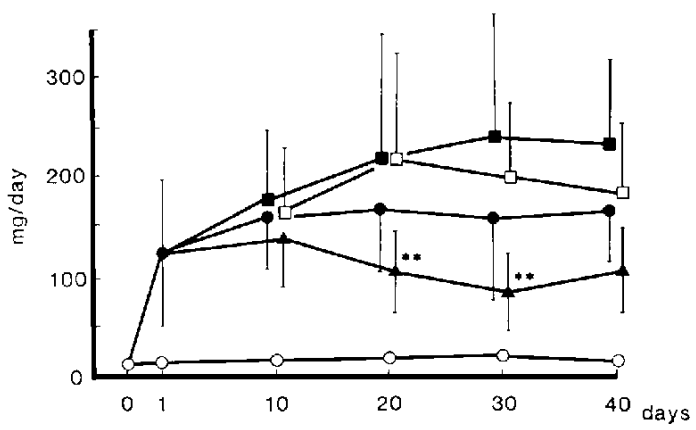

Fig. 3. Effect of OKY-046 on urinary protein content in crescentic-type anti-GBM nephritis in rats. OKY-046 was given daily from the next day of anti-GBM serum injection (day 1) to day 40 . The values are expressed as the mean \pm S.D. obtained from 10 rats in each OKY 046 group, from 16 rats in the normal group, and from 19 rats in the control group. $\bigcirc-O$ : normal: - - control: $\square-\square$ : OKY -046, $0.5 \mathrm{mg} / \mathrm{kg} /$ day, p.o.: $\mathbf{\square}-\mathbf{0}:$ OKY-046, $2.5 \mathrm{mg} / \mathrm{kg} /$ day, p.o. $\mathbf{A}:$ OKY-046, $20 \mathrm{mg} / \mathrm{kg} /$ day, p.o. "* indicates a significant difference from the control at $P<0.01$.

plasma urea nitrogen than the normal rats, and this elevation was significant. The rats administered $20 \mathrm{mg} / \mathrm{kg}$ of OKY-046, but not 0.5 and $2.5 \mathrm{mg} / \mathrm{kg}$ of $\mathrm{OKY}-046$, revealed less urea nitrogen content in comparison with that of the control rats at the end of the experiment.

5. Effect of OKY-046 on platelet aggregability (Fig. 4)

While platelet aggregability in response to collagen was $8.9 \pm 1.8 \Omega$ in the normal rats, the 
Table 2. Effect of OKY-046 on plasma cholesterol content in crescentic-type anti-GBM nephritis in rats

\begin{tabular}{|c|c|c|c|c|}
\hline \multirow{2}{*}{ Groups } & \multirow{2}{*}{$N$} & \multicolumn{3}{|c|}{ Cholestero! content (mg/dl) } \\
\hline & & 8 & 22 & 37 days \\
\hline Normal & 16 & $76.5 \pm 13.9$ & $66.8 \pm 14.8$ & $60.2 \pm 11.8$ \\
\hline Control & 19 & $158.8 \pm 59.8^{\# \#}$ & $130.9 \pm 49.9 *$ & $105.3 \pm 36.0^{\# \#}$ \\
\hline $\begin{array}{l}\text { OKY }-046 \\
0.5 \mathrm{mg} / \mathrm{kg}\end{array}$ & 10 & $187.8 \pm 46.4$ & $169.0 \pm 81.0$ & $119.3 \pm 49.4$ \\
\hline $\begin{array}{l}O K Y-046 \\
2.5 \mathrm{mg} / \mathrm{kg}\end{array}$ & 10 & $196.2 \pm 49.6$ & $159.0 \pm 66.4$ & $125.0 \pm 31.9$ \\
\hline $\begin{array}{l}\text { OKY }-046 \\
20 \mathrm{mg} / \mathrm{kg}\end{array}$ & 10 & $121.0 \pm 27.1$ & $97.4 \pm 20.9^{* *}$ & $91.4 \pm 16.0$ \\
\hline
\end{tabular}

Numbers indicate the mean \pm S.D. \#*s shows a significant difference from the normal rats at $P<0.01$. * shows a significant difference from the control at $P<0.01$.

Table 3. Effect of OKY-046 on plasma urea nitrogen content in crescentic-type anti-GBM nephritis in rats

\begin{tabular}{|c|c|c|c|c|}
\hline \multirow{2}{*}{ Groups } & \multirow{2}{*}{$N$} & \multicolumn{3}{|c|}{ Urea nitrogen $(\mathrm{mg} / \mathrm{dl})$} \\
\hline & & 8 & 22 & 37 Days \\
\hline Normal & 16 & $11.8 \pm 1.5$ & $15.9 \pm 2.5$ & $14.2 \pm 4.0$ \\
\hline Control & 19 & $15.5 \pm 3.1^{\# \#}$ & $16.0 \pm 2.8$ & $17.2 \pm 4.1$ \\
\hline $\begin{array}{l}\text { OKY }-046 \\
0.5 \mathrm{mg} / \mathrm{kg}\end{array}$ & 10 & $17.7 \pm 5.3$ & $17.7 \pm 5.3$ & $19.6 \pm 3.9$ \\
\hline $\begin{array}{l}O K Y-046 \\
2.5 \mathrm{mg} / \mathrm{kg}\end{array}$ & 10 & $20.1 \pm 3.6$ & $18.6 \pm 2.6$ & $20.0 \pm 3.9$ \\
\hline $\begin{array}{l}O K Y-046 \\
20 \mathrm{mg} / \mathrm{kg}\end{array}$ & 10 & $13.2 \pm 1.4$ & $15.1 \pm 1.9$ & $13.6 \pm 1.5^{* *}$ \\
\hline
\end{tabular}

Numbers indicate the mean \pm S.D. \# and show significant differences from the normal rats at $P<0.05$ and $P<0.01 . * *$ shows a significant difference from the control at $P<0.01$.

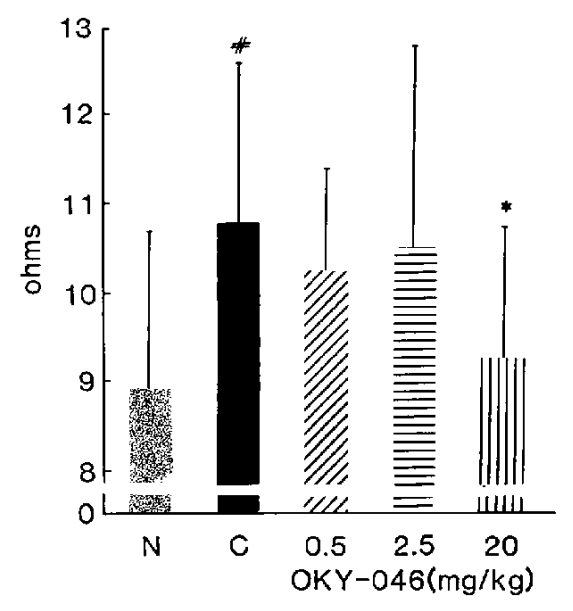

control rats showed an aggregability of $10.8 \pm$ $1.8 \Omega$ on day 40 , which was about $20 \%$ increase over that of the normal rats. Rats administered OKY-046 at $20 \mathrm{mg} / \mathrm{kg}$ had an aggre-
Fig. 4. Effect of OKY-046 on collagen-induced platelet aggregation in crescentic-type anti-GBM nephritis in rats. The values are expressed as the mean \pm S.D. obtained from 10 rats in each OKY-046 group, from 16 rats in the normal group, and from 19 rats in the control group. $\$$ indicates a significant difference from the normal rats at $P<0.05$. indicates a significant difference from the contral at $P<0.05$. $N$ : Normal, C: Control. gability of $9.3 \pm 1.5 \Omega$, corresponding to an inhibitory percentage of $79 \%$, but 0.5 and $2.5 \mathrm{mg} / \mathrm{kg}$ OKY -046 failed to inhibit the aggregation in nephritic rats. 
6. Effect of OKY-046 on histological alteration of glomeruli (Fig. 5, Photo 1)

OKY-046 at $2.5 \mathrm{mg} / \mathrm{kg}$ significantly sup- pressed crescent formation by $55.6 \%$ and fibrinoid necrosis by $44.1 \%$ as compared with the control. OKY-046 at $20 \mathrm{mg} / \mathrm{kg}$ markedly

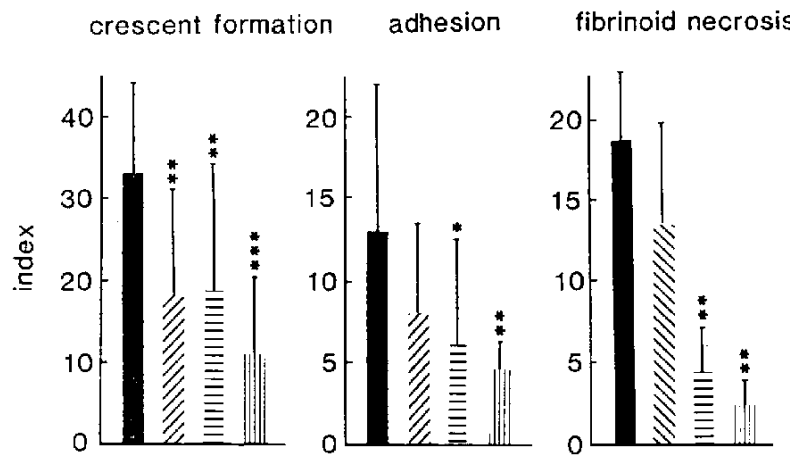

Fig. 5. Effect of OKY-046 on glomerular histopathological parameters on day 40 in crescentic-type anti-GBM nephritis in rats. " $" *$ and $* *$ indicate significant differences from the control at $P<0.05,0.01$

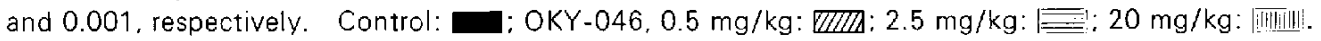
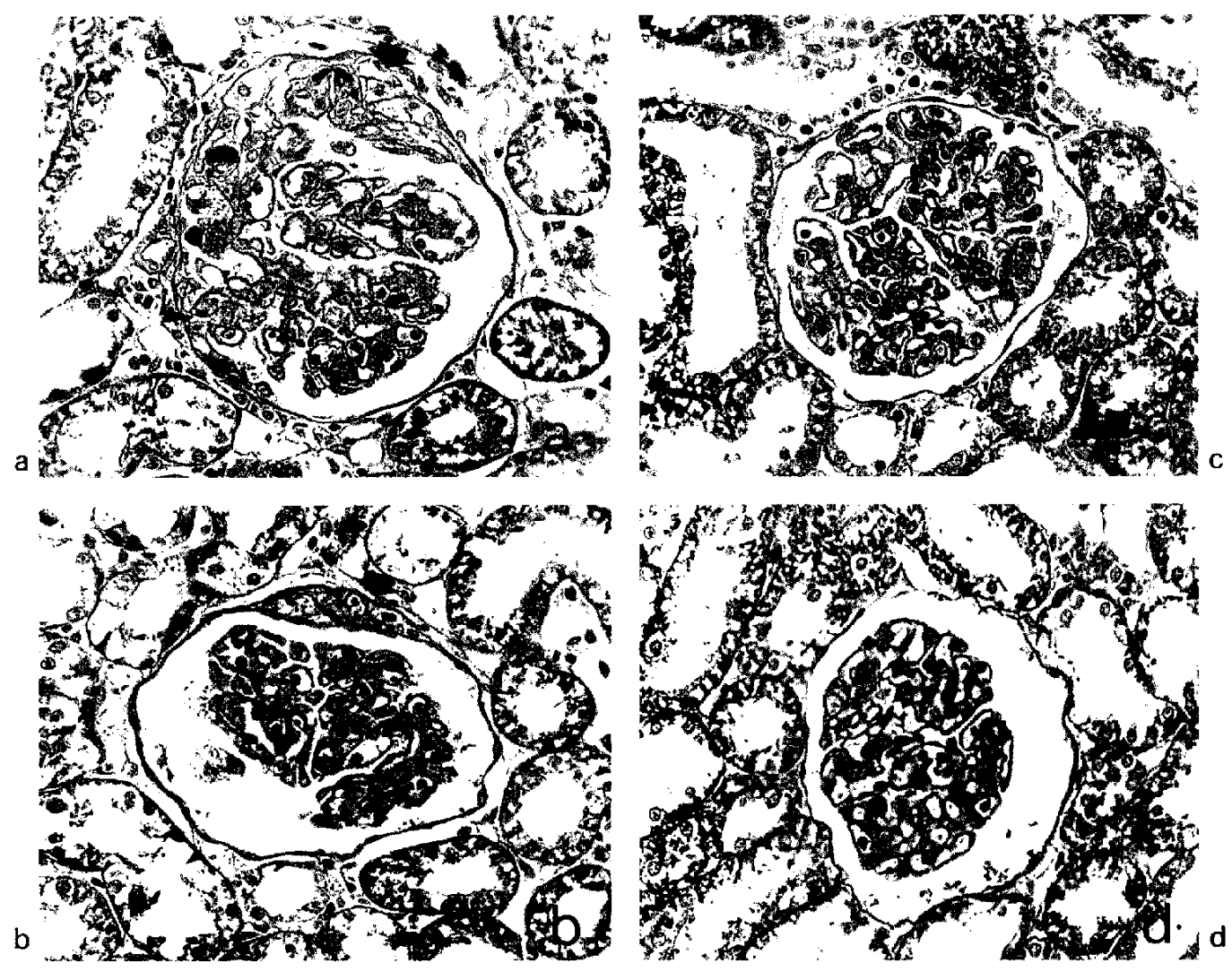

Photo 1. Light micrograph of glomeruli from rats of the control group (a); OKY-046, $0.5 \mathrm{mg} / \mathrm{kg} / \mathrm{daY}$. p.o. group (b): OKY-046. $2.5 \mathrm{mg} / \mathrm{kg} / \mathrm{day}$, p.o. group (c): and $O K Y-046,20 \mathrm{mg} / \mathrm{kg} / \mathrm{day}$, p.o. group (d). Kidneys were obtained at day 40 after the injection of anti-GBM serum. Masson's trichrome stain. $(\times 400)$. Arrow indicates crescent in Bowman's space; the arrow head indicates adhesion. 
protected the glomeruli from these alterations: that is, an inhibitory of $66.2 \%$ percentage in crescent formation, $67.0 \%$ in adhesion to Bowman's capsule of the capillary wall and $87.1 \%$ in fibrinoid necrosis.

\section{Discussion}

In the present studies, notable hyperaggregation in response to collagen was observed in platelets obtained from the rats that were injected i.v. With anti-GBM serum. Additionally, platelets from crescentic-type antiGBM nephritic rats were showed significantly greater aggregability than those from rats with original-type anti-GBM nephritis.

Shibata et al. (28) observed that the endothelium of the glomerular capillary wall was peeled off after the injection of anti-GBM serum into rats. It can be imagined that both reduced production of prostacycline and exposed collagen on the glomerular capillary wall would lead to hyperaggregation of platelets, since the endothelium produces both prostacyclin and an endothelium-derived relaxing factor that inhibit platelet aggregation (29) and collagen is one of the agents that aggregate platelets.

Furthermore, Ujiie et al. have found that the serum $T \times A_{2}$ level was augmented after one hour-incubation of blood from rabbits raised on high-fat chow (23). We think that under nephritic conditions, hyperlipemia takes place, and then the blood level of $\mathrm{TxA}_{2}$ is increased. This increased level of $\mathrm{TXA}_{2}$ makes the platelets more susceptible to activation, especially in the glomerulus, because the endothelial cells of the glomerular capillary wall are impaired by the immune response with anti-GBM antibody as mentioned above.

Since the antibody titer of anti-rabbit IgG was higher in crescentic-type anti-GBM nephritis than in original-type anti-GBM nephritis ( $M$. Ito et al., unpublished data), more antibody would be deposited on the glomerular capillary wall, and a more severe immune response in the glomeruli would be produced than in original-type anti-GBM nephritis (27). Thus, it appears that the differences in antibody production. immunoresponse and the degree of impairing the glomerular capillary wall may be associated with the difference in hyperaggregability of platelets between crescentic- and original types of anti-GBM nephritis in rats.

Ito et al. (27) observed that crescent formation, adhesion to Bowman's capsule of the glomerular capillary wall and glomerular fibrinoid necrosis occurred more frequently in crescentic-type anti-GBM nephritis than in original-type anti-GBM nephritis. Since there is evidence that crescent formation in the glomeruli with anti-GBM nephritis is associated with intraglomerular hypercoagulation $(30,31)$, it is likely that intraglomerular hypercoagulation leads to histological alteration in the glomeruli with anti-GBM nephritis. There is a close relationship between blood coagulation and platelets. Platelet factors III and IV remarkably accelerate the coagulation, although they are not initiators of blood coagulation. Inversely. thrombin promotes the transformation of fibrinogen into fibrin during the coagulating process and it is also strong agent for platelet aggregation. Therefore, inhibiting platelet aggregation is expected to suppress the glomerular alterations in crescentic-type antiGBM nephritis, although we have no available data that directly indicates the relationship between platelet hyperaggregation and crescent formation in the glomeruli.

Additionally, we thought that $\mathrm{T}_{x \mathrm{~A}_{2}}$ produced in the mesangium might be partly responsible for the histological deterioration. The rats with anti-GBM nephritis produced more $\mathrm{TXA}_{2}$ in the glomerulus than did the normal rats (32). In addition, cultured mesangial cells release eicosanoids including $\mathrm{TXA}_{2}$ (33) into the culture medium response to agonists: i.e., angiotensin II (34), vasopressin and A-23187 (14). Mene and Dunn (35) demonstrated the contractile effect of $\mathrm{T} \times \mathrm{A}_{2}$ on cultured rat glomerular mesangial cells by using $T x A_{2}$ and $T x A_{2}$ receptor antagonists. Consequently. $T \times A_{2}$ produced in the mesangium under anti-GBM nephritis may constrict mesangial cells themselves, and aggravate the hemodynamics in the glomeruli.

Thus, we expected that inhibiting the production of $\mathrm{T}_{\times} \mathrm{A}_{2}$ in the mesangium should result in not only the suppression of platelet aggregation but also the dilation of capillary lumen in the glomeruli, and this inhibited the 
progress of histological alterations in rats with crescentic-type of anti-GBM nephritis Actually, in this experiment, a dose-response effect was demonstrated with regard to lightmicroscopic findings in the case of OKY 046 treatment on crescentic-type of antiGBM nephritic rats.

Glomerulonephritis in humans can be divided into various types. The present nephritic model is considered to correspond to rapidly progressive glomerulonephritis which is characterized by crescent formation and hypercellularity in the glomerulus. Therefore, we hope that thromboxane A synthetase inhibitors including OKY-O46 will be a clinically available drug for the treatment of glomerulonephritis of this type.

\section{References}

1 Vassalli, P. and McCluskey, R.T.: The pathogenic role of the coagulation process in rabbit Masugi nephritis. Am. J. Pathol. 45, 653-677 (1964)

2 Briggs, D.J., Kwaan, $\mathrm{H}$. and Potter, E.V.: The role of fibrinogen in renal disease. III. Fibrinolytic and anticoagulant treatment of nephrotoxic serum nephritis in mice. J. Lab. Clin. Med. 74, 715-724 (1969)

3 Nakamoto, Y., Dohi, K., Fujiike, H., Takehisa, Y., Shinoda, A. and Takeuchi, J.: Microangiographic evaluation of the effects of heparin on progressive Masugi nephritis. Kidney Int. 13, 297-305 (1978)

4 Ito, M., Yokochi, E., Kito, T. and Suzuki, Y.: Pharmacological studies on experimental nephritic rats (13). The development and aggravation of nephritis due to the repeated administration of liquid. Folia Pharmacol. Japon. 77. 419-425 (1981) (Abs. in English)

5 Ito, M., Nagamatsu, T. and Suzuki, Y.: Pharmacological studies on experimental nephritic rats (10). Changes in coagulation-fibrinolysis in the course of anti-GBM induced nephritis. Japan. J. Nephrol. 23, 297-308 (1981)

6 Wiggins, R.C. and Glaffelter, A.: Procoagulant activity in glomeruli and urine of rabbits with nephrotoxic nephritis. Lab. Invest. 53, 156-165 (1985)

7 Suzuki, Y., Ito, M., Ogawa, Y. and Nagamatsu, T.: Pharmacological studies on modified type of Masugi's nephritis. Folia Pharmacol. Japon. 75, 585-599 (1979) (Abs. in English)

8 Suzuki, Y., Yamada, H. and Ito, M.: Antinephritic effect of MD-805 [(2R,4R)-4-methyl- $\left[N^{2}-(3-\right.$ methyl-1,2,3,4-tetrahydro-8-quinolinesulfomyl)
L-arginyl]-2-piperidine carboxylic acid monohydrate]. a new antithrombin agent, on crescentic-type anti-GBM nephritis in rats. Japan. J. Nephrol. 26, 1-11 (1984) (Abs. in English)

9 Halpern, P.B., Milliez, P., Lague, G., Fray, A. and Morard, J.C.: Protective action of heparin in experimental immune nephritis. Nature 205, 257-259 (1965)

10 Suzuki, Y. and Ito, M.: Studies on antinephritic action of dipyridamole (1). The effect of dipyridamole on anti-GBM induced nephritis in rats. Japan. J. Nephrol. 23, 323-332 (1981) (Abs. in English)

11 Kincaid-Smith, P., Laver, M.C. and Fairley, K.F.: Dipyridamole and anticoagulants in disease due to glomerular and vascular leasions. Med. J. Aus. 1, 145-151 (1970)

12 Izumino, K., lida, H., Mizumura, Y. and Sasayama, S.: Effect of the antiplatelet agents ticlopidine and dipyridamole on experimental immune complex glomerulonephritis in rats. Nephron 43, 56-61 (1986)

13 Bonvalet, J.P., Pradelles, P. and Farman, N.: Segmental synthesis and actions of prostaglandins along the nephron. Am. J. Physiol. 253 (Renal Fluid Electrolyte Physiol 22). F377F387 (1987)

14 Schlondroff, D. and Ardaillou, R.: Prostaglandins and other arachidonic acid metabolites in the kidney. Kidney Int. 29, 108-119 (1986)

15 Rahman, M.A., Stoke, J.E. and Punn, M.J.: The role of eicosanoids in experimental giomerulonephritis. Kidney Int. 32, Supp. 22, s40-s48 (1987)

16 Hamberg, M., Svensson, J. and Samuelsson, B.: Thromboxanes: A new group of biologically active compounds derived from prostaglandin endoperoxides. Proc. Nat. Acad. Sci. U.S.A. 72, 2994-2998 (1975)

17 Piper, P.J. and Vane, J.R.: Release of additional factors in anaphylaxis and its antagonism by antiinflammatory drugs. Nature 223, 29-35 (1969)

18 Saito, H., Ideura, T. and Takeuchi, J.: Effects of a selective thromboxane $A_{2}$ synthetase inhibitor on immune complex glomerulonephritis. Nephron 36, 38-45 (1984)

19 Stahe, R.A., Adler, S., Baker, P.J., Chen, Y.P., Pritzl, P.M. and Couser, W.G.: Enhanced glomerular prostaglandin formation in experimental membranous nephropathy. Kidney Int. 31, 1126-1131 (1987)

20 Zoja, C., Benigni, A., Verroust, P., Ronco, P., Bertani, T. and Remuzzi, G.: Indomethacin reduces proteinuria in passive Heymann nephritis in rats. Kidney Int. 31, 1335-1343 (1987) 
21 Suzuki, Y., Tsukushi, Y., Ito, M. and Nagamatsu, T.: Antinephritic effect of $Y-19018$, a thromboxane A synthetase inhibitor, on crescentictype anti-GBM nephritis in rats. Japan. J. Pharmacol. 45, 177-185 (1987)

22 Nagamatsu, T. and Suzuki, Y: Experimental immune complex glomerulonephritis and platelet aggregability in whole blood. Japan. J. Inflammation 6, 367-371 (1986) (in Japanease)

23 Ujiie, A., Hiraku, S. and Naito, J.: Pharmacological actions of OKY-046, a specific inhibitor of thromboxane synthetase inhibitor. with special reference to inhibition of thromboxane $\mathrm{A}_{2}$ production and acceleration of prostacyclin production. Pharmacometrics 29. 659-685 (1985) (in Japanease)

24 Bradley, G.M. and Benson, E.S.: Examination of the urine. In Todd-Sanford Clinical Diagnosis by Laboratory Methods, 15th ed., Edited by Davidson, I. and Henry, J.B., p. 74-75, W.B. Saunders Company. Philadelphia (1974)

25 Allain, C.C., Poon, L.S., Chan, C.S., Richmond, W. and Fu, P.C.: Enzymatic determination of total serum cholesterol. Clin. Chem. 20, 470475 (1974)

26 Searcy, R.L. and Cox, F.M.: A modified technique for ultramicro estimation of urea nitrogen. Clin. Chim. Acta 8, 810-812 (1963)

27 Ito, M., Yamada, H., Okamoto, K. and Suzuki, Y.: Crescentic type nephritis induced by antiglomerular basement membrane (GBM) serum in rats. Japan. J. Pharmacol. 33, 1145-1154 (1983)

28 Shibata, S., Sakaguchi, H. and Nagasawa, T.: Exfoliation of endothelial cytoplasma in nephrotoxic serum nephritis. A study using antiserum against water-soluble glycoprotein isolated from the glomerular basement membrane. Lab. Invest. 38, 201-207 (1978)

29 Radomski, M.W., Palmer, R.M.J. and Moncada, S.: The anti-aggregating properties of vascular endothelium: interactions between prostacyclin and nitric oxide. Br. J. Pharmacol. 92, 639-646 (1987)

30 Silva, F.G., Hoyer, J.R. and Plrani, C.L.: Sequential studies of glomerular crescent formation in rats with anti glomerular basement membrane-induced glomerulonephritis and role of coagulation factors. Lab. Invest. 51, 404-415 (1984)

31 Wiggins, R.C. and Gatfelter, T.: Procoagulant activity in glomeruli and urine of rabbits with nephrotoxic nephritis. Lab. Invest. 53, 156-165 (1985)

32 Lianos, E.A., Andres, G.A. and Dunn, M.J.: Glomerular prostagiandin and thromboxane synthesis in rats nephrotoxic serum nephritis. Effects on renal hemodynamics. J. Clin. Invest. 72, 1439-1448 (1983)

33 Knausst, S., Jr.: Immune complexes stimulate prostaglandin and thromboxane synthesis by cultured rat mesangium cells. (abstract) Kidney Int. 31, 325 (1987)

34 Trover, D.A., Kreisberg, J.I., Schwertz, D.W. and Venkatachalam: Effects of vasopressin on phosphoinositides and prostaglandin production in cultured mesangial cells. Am. J. Physiol. 249, F139-F147 (1985)

35 Mene, P. and Dunn, M.J.: Contractile effects of $\mathrm{TxA}_{2}$ and endoperoxide analogues on cultured rat glomerular mesangial cells. Am. J. Physiol. 251, F1029-F1035 (1986) 